\title{
EFICIÊNCIA DE CORTE DE LIMA DE SECÇÃO TRIANGULAR USADA MANUALMENTE E ACOPLADA AO SISTEMA ROTATÓRIO ENDO-GRIPPER
}

\section{FLEXO-FILE CUTTING EFFICIENCY IN THE MANUAL ROOT CANAL TECHNIQUE IN RELATION TO THE ENDO-GRIPPER ROTATORY MOTION}

João Marcelo Ferreira de Medeiros ${ }^{1}$, Nelsa Akemi Ishimoto ${ }^{2}$, Sara Tardelli Alkmin $^{3}$, Pedro Luiz de Carvalho ${ }^{3}$, Vladimir Aparecido Risso ${ }^{2}$, Nivaldo André Zöllner $^{3}$

1 Autor para contato: Universidade de Taubaté - UNITAU, Departamento de Odontologia e Programa de Mestrado em Odontologia sub-área Endodontia, Taubaté, SP;

(11)30883579; jmedeiros@unitau.br

2 Universidade São Francisco - USF, Departamento de Odontologia, Bragança Paulista, SP.

3 Universidade de Taubaté - UNITAU, Departamento de Odontologia, Taubaté, SP.

Recebido para publicação em 13/12/2006

Aceito para publicação em 09/02/2007

\section{RESUMO}

O objetivo deste estudo foi comparar a capacidade e eficiência de corte do instrumento Flexo-File, valendo-se de dentes humanos extraídos antes e após o preparo químico-cirúrgico do canal radicular, utilizando duas técnicas de preparo do canal radicular, a saber: Força Balanceada, utilizada manualmente, e com a utilização do sistema rotatório Endo-Gripper. Foram usadas 40 raízes mésiovestibulares de dentes molares superiores curvos, divididos em dois grupos: grupo I, que foi submetido ao preparo químico-cirúrgico manualmente, valendo-se de limas Flexo-File (\#15 à\#40), utilizando-se a técnica da Força Balanceada; grupo II, em que os canais radiculares foram instrumentados com as limas Flexo-File de mesma numeração, sendo acopladas ao contra-ângulo do aparelho Endo-Gripper. De posse dos resultados obtidos, concluiu-se que não ocorreram variações no desgaste dentinário, quando do preparo do canal radicular, em função da técnica de instrumentação (manual e mecânica) com a lima Flexo-File. Relativamente ao tempo gasto para o preparo do canal radicular, não ocorreu diferença estatisticamente significante entre a instrumentação manual e automatizada. Também não se observou diferença estatística significante com relação ao índice de eficiência de corte em ambas as técnicas ( $\mathrm{p}>0,05)$.

Palavras-chave: instrumentação, endodontia, tratamento do canal radicular. 


\begin{abstract}
The purpose of this investigation was to compare the cutting ability and the efficiency of a Flex-File instrument on extracted human teeth before and after the root canal preparation throught the use of two techniques, the manual balanced force technique instrumentation and the engine-driven rotatory motion (EndoGripper) system. Forty mesio-buccal roots of curved maxillary molar teeth were divided into two groups. The first group was submitted to the manual technique, while the second group was submitted to the rotatory motion instrumentation. The results showed there were no variations between the techniques in what refers to the dentin removing ability during the root canal preparation, nor in the time spent in the preparation of the root canal. There were no statistically significant differences in the cutting efficiency in both techniques $(p>0,05)$ either.
\end{abstract}

Key words: instrumentation, endodontics, root canal therapy

\section{Introdução}

A instrumentação do canal radicular engloba a remoção do conteúdo eventual do canal radicular por meio de manobras promotoras de limpeza e modelagem (Lage-Marques e Antoniazzi, 2002; Paiva eAntoniazzi, 1991) até a criação de forma adequada de modo a possibilitar obturação correta.

No que tange à escolha do instrumento, importa considerar, além de suas propriedades físicas, a forma e a capacidade de corte (Bombana, 1986; Tapel et al. 1995a; Tapel et al. 1995b; Souza et al.,1998; Medeiros et al. 2000). Cumpre salientar que a capacidade de corte do instrumento depende das propriedades do material empregado e das características de fabricação (Berger, 2002; Tapel e Schäfer, 1997).

Neste sentido, deve-se associar as características e propriedades desses instrumentos usando-os de maneira racional e integrando-os as técnicas manuais de preparo do canal radicular curvo especialmente as técnicas escalonadas.

Roane et al. (1985) preconizaram a técnica da força balanceada cujo desenvolvimento é prático e extremamente simples representando um procedimento incluído nas modernas técnicas de preparo do canal. Deve ser executada com a utilização de limas com pontas modificadas, sem corte na extremidade.

Essa técnica possibilita movimento rotacional recíproco, ou seja, no sentido horário e anti-horário explorando o canal radicular a fim de facilitar a introdução do instrumento até o comprimento de trabalho. Faz-se a rotação no sentido horário (1/8 de volta), sem que haja pressão apical, com o objetivo de inserir o instrumento levemente na dentina, e a seguir promove-se rotação no sentido anti-horário (1/2 volta).

Além disso, Levy e Abou-Rass (1990) e Serene et al. (1995) ressaltam que inúmeras são as vantagens da instrumentação automatizada: a instrumentação do canal radicular é realizada sem pressão exagerada por parte do instrumento, maior rapidez do que a técnica usada manualmente facilitando a remoção de debris e resultando em preparo com formato uniforme, paredes superficiais lisas com menor stress do operador.

Por outro lado, há que se considerar que o instrumento deve apresentar propriedades, e dentre elas destacam-se a capacidade e eficiência de corte. No que respeita sua avaliação diversos métodos têm sido utilizados.

Os instrumentos de secção transversal triangular apresentam vantagens sobre os de secção quadrangular no tocante à capacidade e eficiência de corte. Sendo assim àqueles de secção triangular removem mais debris, graças à profundidade de sua lâmina de corte maior, maior capacidade de corte por suas arestas cortantes apresentarem um ângulo mais agudo, são mais flexíveis por apresentarem secção transversal com menor áreas e tem memória elástica, atuando com menor pressão na superfície externa da curvatura apical, e conseqüentemente, produzindo menor desvio apical.

Além do mais, melhores resultados são obtidos 
quando realizam previamente o preparo cervical facilitando sobremaneira o preparo do canal radicular obtendo-se melhores resultados no que respeita ao formato final da preparação, desvio apical e extrusão de material além do forame apical. Confirmam os autores mesmo que não haja significado estatístico em relação à realização do preparo cervical, tal procedimento indiscutivelmente facilitará o emprego dos instrumentos em rotação alternada (Sydney et al., 1994).

Cumpre relatar a atuação dos instrumentos endodônticos no que respeita a capacidade e eficiência de corte durante o preparo do canal radicular.

Assim, vários tipos de instrumentos têm sido utilizados na prática clínica de maneira especial os de secção triangular como a lima Flexofile fabricada em aço inoxidável de grande utilidade e uso pelos especialistas e clínicos gerais.

Aliás, os instrumentos de secção triangular removem mais debris, graças à profundidade de sua lâmina de corte, possui maior capacidade de corte por suas arestas cortantes e apresentam um ângulo mais agudo. É um instrumento mais flexível resultado de menor área de secção transversal e quando atuam determinam menor pressão da superfície externa da curvatura apical produzindo menos desvio dessa área.

Morrison et al. (1989) investigaram o efeito do emprego e da esterilização a vapor sobre a eficiência de corte de 55 limas endodônticas tipo Flexofile \#25 em 160 primeiros e segundos molares superiores e inferiores humanos extraídos. Usaram aparelho linear e o substrato utilizado uma tira de resina fenólica de $102 \mathrm{~mm}$ de comprimento, $19 \mathrm{~mm}$ de largura e 0,5 mm de espessura. Após isso, um instrumento escolhido ao acaso de cada grupo controle e dois instrumentos de cada grupo experimental foram analisados no microscópio eletrônico de varredura e as áreas de interesse foram então aumentadas 300 vezes e fotografados. Um instrumento Flexofile \#25 sem uso foi fotografado a um aumento de 60 e 300 com o microscópio eletrônico. O instrumento foi usado na instrumentação de cinco molares da mesma maneira que os instrumentos do grupo experimental. A seguir a lima foi microfotografada com 60 e 300 aumentos no microscópio eletrônico. O mesmo instrumento foi usado para realizar preparo em cinco dentes molares adicionais seguido de análise do microscópio eletrônico de 60 a 300 aumentos.
De seus resultados constam que, não ocorreram diferenças significativas entre os instrumentos do grupo experimental utilizados para instrumentar um molar e aqueles usados por cinco ou 10 molares. A diferença na eficiência de corte entre o segundo e terceiro grupos experimentais não foi significante indicando que a maior diminuição no corte ocorreram com o uso entre um e 5 molares. Nenhuma diferença significativa foi encontrada entre os grupos controles indicando nenhuma diminuição na eficiência de corte pela esterilização exclusiva. Consideraram que as freqüentes esterilizações no aço inoxidável, empregando qualquer dos meios pelo calor, não ocasionaram corrosão, enfraquecimento nem tampouco dificuldades no que tange ao seu manuseio durante a rotação.

Souza et al. (1998) cotejaram a eficiência de corte de quatro instrumentos endodônticos (Flex-R, Mor-Flex, Flexofile e lima tipo K) de numeração \#20, \#25 e \#30 considerando o decréscimo do rendimento ocorrido do primeiro ao décimo uso. Utilizaram dispositivo especialmente desenvolvido de sorte a simular o movimento de limagem manual utilizado na instrumentação dos canais radiculares eliminando com isso a interferência do operador. Foram utilizados 72 instrumentos endodônticos na porção média de sua parte ativa. Concluíram os autores que a lima tipo K foi o instrumento que apresentou menor capacidade de corte que as demais, não ocorrendo diferença significativa entre as limas Flex-R, Mor-Flex e Flexofile. Em relação ao uso, verificou-se que, após seu primeiro emprego, a lima perde significativamente a eficiência de corte, perda esta que continua progressivamente à medida que o instrumento vai sendo utilizado.

Schäfer (1999) comparou a eficiência de corte das limas de aço inoxidável com diferentes secções transversais (quadrangular, triangular, rombóide, "S" e da lima Hedströen). As limas foram acionadas por movimento de limagem e rotação por meio de aparelhos que simulavam esses movimentos em canais artificiais cilíndricos em acrílico. A eficiência de corte realizado por movimento de rotação foi mensurada por meio de profundidade de penetração máxima. Concluiu o autor que os instrumentos de secção quadrangular apresentaram o pior desempenho quando comparadas as de secção triangular e romboidal.

Pallotta et al (1999) avaliaram o poder de corte 
das limas de níquel-titanio (Nitflex) comparando-as com limas de aço inoxidável, Flexofile. Na metodologia, utilizou dentes naturais instrumentados com o auxilio de um aparelho que permitia transmitir ao instrumento constantes movimentos de vai-e-vem com tempo, velocidade, freqüências e tensão controladas. As amostras eram pesadas antes e após o preparo, obtendo dessa maneira as respectivas diferenças de peso dos corpos de prova. Concluem os autores que, o poder de corte da limas Nitflex é significativamente menor em relação as tipo Flexofile para as limas de calibre 25, 35 e 30 e não significante para os demais calibres.

Medeiros et al. (2000) avaliaram a capacidade de corte de limas de secção triangular em aço inoxidável e de primeiro uso (Flex-R) mediante o emprego de duas técnicas de preparo de canal radicular curvo em quarenta dentes molares humanos extraídos realizando dupla pesagem em balança analítica antes e depois do preparo dos canais radiculares. Ocorreu diferença estatisticamente significante com relação à quantidade de dentina removida entre as técnicas da força balanceada e seriada com recuo programado.

Silva (2001) averiguou a capacidade de corte de instrumentos endodônticos tipo Flexofile e Nitiflex com dispositivo de simulação com movimento linear de vai-e-vem dos instrumentos sobre placas de osso bovino em um ciclo de quarenta e cinco minutos por placa divididos por nove entalhes pré-existentes. Os instrumentos confeccionados em aço inoxidável exibiram maior capacidade de corte e em termos de rendimento mostraram-se com decréscimo mais rápido que as limas de níquel-titânio.

Amaral (2002) confrontou a capacidade de corte de limas de aço inoxidável (Flexofile) com limas fabricadas em níquel-titânio (Nitiflex). Amparado praticamente na metodologia realizado por Silva (2001) o referido autor concluiu de maneira inversa que as limas Nitiflex possuem poder de corte maior do que as limas Flexofile perdendo ambas a capacidade de corte em função do número de uso sendo esta perda mais significativa principalmente do primeiro para o segundo uso.

Com vistas a averiguar a possível influência da esterilização e de múltiplos usos sobre a superfície de corte de 36 limas Flexofile, Medeiros et al. (2002) utilizaram dentes incisivos inferiores e raízes mésio- vestibulares de molares superiores sendo os instrumentos avaliados em microscopia eletrônica de varredura. Foram divididos em grupos, a saber: 12 limas as quais foram esterilizadas, porém, não usadas sendo 6 limas do primeiro grupo esterilizadas em estufa, 6 limas do segundo grupo esterilizadas em auto-clave; 12 limas utilizadas para o preparo do canal radicular na raiz mésio-vestibular de molares superiores sendo 6 limas esterilizadas em estufa e 6 limas esterilizadas em autoclave e 12 limas utilizadas para o preparo do canal radicular em dentes incisivos inferiores sendo 6 limas esterilizadas em estufa e 6 limas esterilizadas em autoclave. Todos os instrumentos utilizados no preparo do canal radicular em primeiro uso foram repetidos em segundo, terceiro e quarto usos, em ambas as amostras. Concluem os autores que, os instrumentos usados na preparação do canal radicular especialmente nas raízes curvas sofreram maiores desgastes quando comparados com os canais retos principalmente aquelas de menores diâmetros a exemplo da lima de número 15. Relativamente às duas esterilizações não se observaram danos na parte ativa dos instrumentos não havendo diferença no que respeita desgaste da parte ativa em ambos os métodos.

Claro (2004) comparou os efeitos sobre a resistência ao desgaste dos instrumentos submetidos ao tratamento de implantação de íons por imersão em plasma, como limas não tratadas de aço inoxidável e de níquel-titânio. Para tanto, valeu-se de limas Flexofile calibre 35 e de comprimento $25 \mathrm{~mm}$ de aço inoxidável e limas endodônticas Nitiflex de níquel-titânio de mesmo número e tamanho. Foi desenvolvida placa de baquelite a qual sofria desgaste por meio de um dispositivo motorizado o qual tinha por finalidade impor movimentos de vai-vem da lima Flexofile (\#35) e Nitiflex (\#35). A resistência ao desgaste das limas foi determinada in vitro valendo-se de um dispositivo motorizado para aplicação de movimentos horizontais de limagem sobre placas confeccionados de resina fenólica de fixação a quente. A resistência ao desgaste das limas de níquel-titânio submetidas ao tratamento de implantação iônica é significativamente maior do que a resistência ao desgaste das limas de aço inoxidável e as limas de níquel-titânio não tratadas não provocaram alteração significativa na flexibilidade das limas de níquel-titânio. 
Borges (2005) avaliou a capacidade de corte de dois instrumentos endodônticos de base quadrangular (tipo K) e de base triangular (Flexofile) de dois fabricantes confeccionados em aço inoxidável. Quarenta limas por meio de movimento linear padronizado foram usadas e para tanto preparou vinte placas de resina fenólica (baquelite) providas de cinco canaletas em seus bordos superior e inferior respectivamente, que serviram de guia para os desgastes efetuados pelos instrumentos. Foram feitas análises em um projetor de perfil, para verificar a capacidade de corte dos instrumentos. Concluiu que, as limas Flexofile de secção triangular posuem maior capacidade de corte que as limas tipo K-File de secção quadrangular.

Franco (2005) comparou a capacidade de corte do instrumento Flexofile em canais simulados considerando a diferença de seus pesos, antes e após o preparo químico-cirúrgico do canal radicular. Para tanto, valeu-se de 20 canais simulados confeccionados em blocos de resina fenólica (baquelite) tendo como fonte de variação duas técnicas de preparo do canal radicular, a saber: uma técnica manual e outra, auto-matizada, com a utilização do sistema rotatório Endo-Gripper sendo os blocos pesados antes e depois do preparo do canal radicular. Houve diferença em resposta ao preparo do canal simulado dos blocos confeccionados em resina fenólica quando comparados às técnicas de instrumentação manual com o instrumento Flexofile ea técnica automatizada com rotação alternada valendose do mesmo instrumento acoplado ao sistema EndoGripper. Todos os blocos de resina fenólica sofreram desgaste e, por conseguinte, perda de peso em função do número de uso dos instrumentos para as duas técnicas de preparo do canal empregadas; e os instrumentos tipo Flexofile em ambas as técnicas perderam a capacidade de corte em função do número de uso.

O objetivo do presente estudo foi averiguar, comparativamente, a capacidade de corte de instrumentos da linha de limas de secção triangular e o tempo gasto para preparo dos canais, em dentes humanos extraídos, considerando a diferença de seus pesos, antes e após o preparo químico-cirúrgico do canal radicular, tendo como fonte de variação duas técnicas de preparo do canal radicular, a saber: uma, a Força Balanceada utilizada manualmente e outra, automatizada, com a utilização do sistema rotatório Endo-Gripper.

\section{Material e Método}

Foram selecionados 40 canais mésio-vestibulares de molares superiores humanos, extraídos por razões diversas de diferentes graus de curvaturas. Após o exame visual e radiográfico os portadores das seguintes condições tais como: ápice aberto, raízes extranumerárias, reabsorção radicular externa e interna, curvaturas acentuadas e canais tratados endodonticamente foram eliminados.

Após limpeza, os referidos dentes foram armazenados em solução fisiológica de cloreto de sódio $0,9 \%$ na câmara de incubação, durante 72 horas a $37^{\circ} \mathrm{C}$.

Efetuou-se a cirurgia de acesso dos dentes, com pontas diamantadas esféricas \# 1019, em alta-rotação. Usaram-se brocas de Batt \#12 e \#14, acopladas em baixa-rotação para o aplainamento das paredes, desgaste cervical com broca de Gates-Glidden número \#1 de $32 \mathrm{~mm}$, seguiu-se os procedimentos de irrigação com soro fisiológico e de esvaziamento do canal radicular com limas tipo K de diminuto calibre \#8 e \#10, para remoção de material que eventualmente possa ter sido levado para o interior do canal radicular durante o preparo cervical. As raízes mésio-vestibulares que permitiram a entrada da lima tipo K\#15 em todo seu comprimento e que fosse verificada certa justeza foram escolhidas totalizando 40 dentes, efetuando-se novamente irrigação com soro fisiológico.

Os dentes foram armazenados em frascos individuais numerados de 1 a 40 e levados para desidratação na câmara de incubação acima descrita a $37^{\circ} \mathrm{C}$ durante 7 dias.

Promoveu-se dupla pesagem em balança analítica de precisão, cuja média aritmética forneceu o peso inicial (P1).

Após isso, os dentes foram re-hidratados no soro fisiológico na câmara de incubação a $37^{\circ} \mathrm{C}$ por 72 horas.

O limite da instrumentação, para cada dente, foi determinado introduzindo instrumento tipo K\# 15 no canal radicular e com o auxílio de lente de 10 aumentos verificou-se a coincidência da ponta do instrumento com o forame apical.

Dividiram-se os dentes aleatoriamente em dois grupos iguais de vinte amostras cada: grupo I - foi submetido ao preparo químico-cirúrgico manualmente 
valendo-se de limas Flexofile(\#15 à \#40) utilizando-se a técnica da Força Balanceada proposta por Roane et al. (1985); grupo II - os canais radiculares foram instrumentados com as limas Flexofile de mesma numeração sendo acopladas ao contra-ângulo do aparelho EndoGripper. As duas amostras foram instrumentadas por único operador, especialista em Endodontia e com experiência em automação.

Nos dois grupos empregou-se como substância química auxiliar da instrumentação a solução de hipoclorito de sódio a $1 \%$, estabilizada com cloreto de sódio.

Registrou-se o tempo gasto acionando um cronômetro tanto no início da instrumentação manual quanto da automatizada sendo interrompido durante as trocas das limas. Foram realizadas a limpeza dos instrumentos com gaze embebida em álcool, e ao final da instrumentação com a lima \#40, somou-se o tempo total despendido.

O critério de mudança do instrumento para outro de maior calibre ocorreu quando o instrumento anterior mostrou-se livre no canal radicular o mesmo valendo para o último instrumento.

Findo o preparo químico-cirúrgico, realizou-se irrigação com 10 mililitros de solução de hipoclorito de sódio 1\% e mais 10 mililitros de EDTA-T, retornando o dente ao seu frasco de origem para nova desidratação por um período de 7 dias na câmara de incubação a $37^{\circ} \mathrm{C}$. Após esse tempo promoveu-se a nova dupla pesagem cuja média aritmética originou o peso final (P2).

Uma vez obtidos os valores P1 e P2 para cada dente, realizou-se subtração do segundo valor do primeiro, o que forneceu a quantidade de dentina removida durante o preparo químico-cirúrgico. Os dados foram submetidos à análise estatística, aplicando o teste t de Student ao nível de 5\% de significância.

\section{Resultados}

De posse dos resultados obtidos, elaborou-se a Tabela 1 a qual sofreu tratamento estatístico dos valores relativos às perdas de peso (miligrama) decorrentes, tanto da instrumentação manual quanto da automatizada, tempo despendido de ambas instrumentações (minutos) bem como o índice de eficiência de corte (miligrama/minuto), médias, desvio padrão e coeficiente de variação das referidas grandezas.

Tabela 1 - Média $(\bar{X})$, desvio padrão (DP) e coeficiente de variação (CV) dos grupos em relação às grandezas desgaste, tempo gasto e da eficiência de corte (EC).

\begin{tabular}{|c|c|c|c|c|c|c|c|c|c|}
\hline \multicolumn{10}{|c|}{ REMOÇÃO } \\
\hline \multirow{2}{*}{ GRUPO } & \multicolumn{3}{|c|}{$\begin{array}{l}\text { QUANTIDADE DE } \\
\text { DESGASTE }\end{array}$} & \multicolumn{3}{|c|}{ TEMPO } & \multicolumn{3}{|c|}{$\mathbf{E} \mathbf{C}^{*}$} \\
\hline & $\bar{x}$ & $\begin{array}{l} \pm \mathrm{DP} \\
(\mathrm{mg})\end{array}$ & $\begin{array}{l}\mathrm{CV} \\
(\%)\end{array}$ & $\bar{x}$ & $\begin{array}{l} \pm \mathrm{DP} \\
(\mathrm{min})\end{array}$ & $\begin{array}{l}\mathrm{CV} \\
(\%)\end{array}$ & $\bar{x}$ & $\begin{array}{c} \pm \mathrm{DP} \\
(\mathrm{mg} / \mathrm{min})\end{array}$ & $\begin{array}{l}\mathrm{CV} \\
(\%)\end{array}$ \\
\hline I (Manual) & 32,9 & 7,6 & 23 & 3,8 & 1,0 & 27 & 9,4 & 3,1 & 33,1 \\
\hline \multirow[t]{2}{*}{ II (Automatizado) } & 35,4 & 7,7 & 21,9 & 3,8 & 0,6 & 14,7 & 9,6 & 2,6 & 26,7 \\
\hline & \multicolumn{3}{|c|}{$\mathrm{T}=1,06$ (n. s.) } & \multicolumn{3}{|c|}{$\mathrm{T}=0,02$ (n. s.) } & \multicolumn{3}{|c|}{$\mathrm{t}=0,29$ (n. s.) } \\
\hline
\end{tabular}




\section{Discussão}

Constitui fato perfeitamente aceito que a instrumentação do sistema de canais radiculares promove a remoção de dentina infectada da superfície do canal radicular, atividade esta exclusivamente realizável através da instrumentação (Pesce, 1990).

Sendo assim, tal eficiência do preparo do canal radicular é feita em função da escolha de instrumento de reconhecida capacidade de corte, devendo-se aliar, ao mesmo tempo, uma técnica adequada de instrumentação, uso de substância química auxiliar não dispensando a destreza do operador.

Com vistas à escolha de técnica adequada a instrumentação de canais radiculares curvos, cumpre salientar o alargamento cervical prévio ao preparo químico cirúrgico do canal radicular uma vez que tal manobra possibilita vantagem ao criar uma zona de escape em nível cervical o que possibilita quando da irrigação-aspiração maior arraste e refluxo de raspas de dentina impedindo extrusão de material removido da parede do canal em direção ao forame apical.

Moveu-nos a intenção de comparar, nesta pesquisa, a capacidade eficiência de corte de um tipo de instrumento, de secção triangular, valendo-se da técnica da força balanceada realizada manualmente e do sistema de rotação alternada acoplando o mesmo instrumento.

É importante elucidar que as médias dos pesos iniciais das amostras, em gramas, antes da instrumentação manual e instrumentação automatizada foram tomadas após o preparo da câmara pulpar, mormente depois do preparo cervical.

Tal ocorrência, como bem salientam Estrela et al. (1992) deve-se entre outras razões à aposição de dentina na região cervical do que resulta em estreitamento do canal radicular, dificultando a penetração da lima no seu comprimento de trabalho. Aconselha o referido autor que o alargamento da entrada do canal radicular antes da instrumentação remove tais interferências, o que facilita essa manobra.

Com este pretexto, no nosso experimento, executou-se em todas as amostras o alargamento cervical ou desgaste compensatório com as brocas GatesGlidden previamente à instrumentação, uma vez que este passo permite que o instrumento entre de forma mais livre e direta no interior do canal permitindo maior contato com a superfície da parede dentinária resultando em menor pressão na porção externa da curvatura apical.

Em ambas as técnicas de instrumentação, o alargamento cervical foi efetuado previamente à instrumentação, visto que pretendíamos mensurar o desgaste ou a remoção dentinária efetuada pelo instrumento e não pelo preparo cervical com a broca Gates-Glidden.

Sydney et al. (1994), Tepel et al. (1995b) e Berger (2002) esclareceram que os efeitos resultantes da feitura do preparo cervical prévio a instrumentação do canal radicular, permite obter melhores resultados no acabamento final da cavidade endodôntica.

Outro detalhe diz respeito à padronização da pesagem em função da secagem dos dentes após a hidratação, uma vez realizado, o preparo químico cirúrgico do canal radicular (Pesce, 1990; Hannequin et al.1992; Medeiros et al. 2000).

Assim, optamos no presente estudo pela pesagem dos dentes desidratados e isto representou uma acertada padronização do peso dos dentes e da menor variação obtida dos pesos. Além disso, a pesagem do dente desidratado possibilita a remoção do excesso de líquido na luz do canal radicular, na superfície externa do dente e nos canalículos dentinários, fato esse que não ocorre quando se realiza a pesagem logo após a secagem interna do conduto com bomba a vácuo e cones de papel absorvente, seguida da secagem externa com papel filtro. Julgamos que a câmara de incubação utilizada para tal finalidade, regulada a $37^{\circ} \mathrm{C}$ por um período de sete dias, cumpriu com este objetivo realizando, aliás, pesagem dupla tanto no início quanto no final da instrumentação.

Isto corrobora com os achados de Hennequin et al., que utilizaram pesagem de raízes desidratadas observando indução de fissuras na dentina, o que poderia motivar variações nos pesos dos dentes. Ponderam os referidos autores que houve um decréscimo de perda de peso diária na primeira semana, sendo que o maior decréscimo ocorreu nos primeiros dias de pesagem. O total de perda de peso no terceiro dia de desidratação foi maior que o obtido após a instrumentação e, após esse período, a perda de peso foi aleatória não seguindo um padrão. As amostras foram hidratadas antes da instrumentação para aproximar-se das condições clínicas. 
Os fatos anteriormente colocados revelam que, tanto a pesagem prévia como a pesagem posterior ao preparo químico-cirúrgico dos canais radiculares dos dois grupos expressa de modo convincente o efeito da remoção quantitativa da instrumentação.

Na tabela 1 verifica-se que para a grandeza da quantidade de dentina removida, observaram-se as médias, desvio padrão e coeficiente de variação com valores numericamente homogêneos e valor calculado do teste t-Student igual a 1,06, o que significa que podemos afirmar, no nível de significância de $5 \%$, que a proporção de amostras de cada técnica de instrumentação não diferem entre si.

Com relação ao tempo gasto para realização da instrumentação, verificou-se que apesar das médias apresentarem-se numericamente iguais, o desvio padrão se apresentou com valores numericamente heterogêneos. No entanto os coeficientes de variação indicaram para a instrumentação manual uma maior heterogeneidade de tempo despendido no preparo. Do mesmo modo que o valor calculado do teste t-Student foi igual a 0,02, entendemos que, no nível de significância de 5\%, a proporção do tempo decorrido durante a instrumentação manual não difere da proporção do tempo decorrido durante a instrumentação automatizada.

Com relação à grandeza índice de eficiência de corte da mesma forma, foram homogêneos para ambas as técnicas e, portanto com valor calculado do teste t-Student de 0,29, assinalando que em nível de significância de 5\%, o índice de eficiência de corte representado pela quantidade de dentina removida em miligramas por unidade de tempo minuto não difere tanto para a instrumentação manual como para a instrumentação mecânica.

Além disso, a referida tabela fornece dados que nos leva a deduzir após a análise estatística que, a instrumentação das duas técnicas apresentaram resultados similares, no entanto o coeficiente de variação da grandeza tempo quando da utilização da técnica manual indicou irregularidade que se traduz por variação maior do tempo despendido.

Procurou-se escolher profissional especialista em Endodontia e habilitado em sistemas automatizados, porquanto sua experiência e grau de conhecimento como bem salientam Pesce (1990) e Pessoa (1993) de modo a evitar variações de rendimento e propiciar maior eficiência no que diz respeito ao desgaste dentinário.

No que diz respeito à escolha do sistema EndoGripper para esta pesquisa, foi feita por representar custo relativamente baixo se comparado aos outros sistemas automatizados, além de permitir a adaptação de limas convencionais no contra-ângulo sem a necessidade de qualquer adaptação e possuir rotação alternada de 45 graus, cinemática essa semelhante à instrumentação da técnica da Força Balanceada indicando sua utilização para os profissionais que estão se iniciando com os sistemas rotatórios.

Para mais a escolha recaiu em instrumentos de secção triangular porquanto removem mais debris do que instrumentos de secções quadrangulares graças à profundidade de suas lâminas de corte. Possui maior capacidade de corte por suas arestas cortantes e apresentam um ângulo mais agudo. É um instrumento mais flexível resultado de menor área de secção transversal e quando atuam determinam menor pressão da superfície externa da curvatura apical produzindo menos desvio dessa área especialmente durante a realização da técnica da Força Balanceada (Souza et al., 1998; Schäfer, 1999; Medeiros et al., 2000; Medeiros et al., 2002; Borges 2005); maior capacidade de corte quando comparada com o tipo de liga utilizada no seu fabrico a exemplo da liga de níquel-titânio (Pallotta et al., 1999; Silva 2001) embora haja discordância de Amaral (2002).

Diga-se a propósito que os resultados da nossa pesquisa são concordantes com aquelas obtidas por Franco (2005) ao fazer uso do mesmo instrumento em preparo manual e automatizado em rotação alternada e com o mesmo aparelho em canais simulados confeccionados em resina fenólica (baquelita) ao contrário do nosso trabalho que foi realizado em dentes humanos extraídos.

Com vistas a este material utilizado pelo autor supracitado, Claro (2004) investigou a esse respeito do que resultou em um avanço em relação à obtenção de blocos destinados a canais simulados, uma vez que, o acrílico representado pelo polimetilmetacrilato ao ser testado através de testes de microdureza Vickers de placas de desgaste possui baixa dureza e alta ductibilidade respondendo ao ciclo de desgaste sem qualquer 
perda de peso quando sofreu processo de limagem com os instrumentos endodônticos.

Além do mais, dentre os materiais pesquisados neste estudo as placas de acrílico apresentaram valor médio de microdureza menor do que as placas de baquelite, osso de fêmur bovino desidratado e osso de fêmur bovino úmido.

Percebemos ainda para as duas técnicas avaliadas houve perda que se traduz em remoção de dentina durante a instrumentação do canal radicular o que denota para as duas técnicas utilizadas, a capacidade de corte do instrumento de configuração triangular, mesma procedência, mesma constituição metalúrgica, mesmo índice de conicidade, mesmo número de espiras e mesma flexibilidade não representaram quantitativamente igualdade de desgaste nas amostras testadas. Por outro lado, Pesce (1990), quando utilizou dois instrumentos de diferentes procedências (Flexofile e Trifile) e de mesma área seccional triangular verificou a ocorrência de variações da capacidade de corte dos referidos instrumentos.

Não obstante o aparelho de rotação alternada Endo-Gripper realize movimento de rotação constante do instrumento é de se esperar que a amplitude e a freqüência de movimentos realizados pelo profissional podem promover variações involuntárias durante a preparação com o aparelho do que resulta remoção de dentina das amostras testadas com valores diferentes.

\section{Conclusões}

Não ocorreram variações no desgaste dentinário quando comparada à técnica de instrumentação manual e a técnica automatizada em rotação alternada valendose do instrumento de secção triangular.

Não houve diferença quanto ao tempo despendido entre as técnicas de instrumentação manual com instrumento de secção triangular e a técnica automatizada em rotação alternada valendo-se do EndoGripper acoplado ao contra-ângulo com o mesmo instrumento. Porém, na instrumentação manual ocorreu maior heterogeneidade no tempo gasto, como indicado pelo coeficiente de variação das duas técnicas.
Não ocorreu diferença com relação ao índice de eficiência de corte em ambas as técnicas.

\section{REFERÊNCIAS}

1. AMARAL, G. Avaliação da capacidade de corte de limas tipo kerr em liga de aço inxidável ou em liga de níquel titânio. Taubaté, 2002. 89p. Dissertação (2002. Mestrado em Endodontia) - Departamento de Odontologia da Universidade de Taubaté.

2. BERGER, C.R. Endodontia Clínica. São Paulo: Pancast, 2002. 571p.

3. BOMBANA, A.C. Análise química (quantitativa) das ligas de aço inoxidável de alguns instrumentos endodônticos de diferentes tipos e procedimentos. (Contribuição ao estudo). São Paulo, 1986. Tese (Doutoramento) - Faculdade Universidade de São Paulo, 1986.

4. BORGES, T. F. Avaliação da capacidade de corte de limas de seção reta transversal quadrangular e triangular em liga de aço inoxidável. Taubaté, 2005. 75 f. Dissertação (Mestrado em Odontologia) - Departamento de Odontologia da Universidade de Taubaté.

5. CLARO, F. A. E. Avaliação de desempenho de limas endôdonticas de níquel-titânio após tratamento de superfície. Taubaté, 2004. 108f. Dissertação (Mestrado em Engenharia Mecânica) Faculdade de Engenharia Mecânica da Universidade de Taubaté.

6. ESTRELA, C.; WETZEL, I.F.; PESCE, H.F. Proposição de uma técnica do preparo cervical para canais radiculares curvos. Rev. Odontol. Bras. Central v.2, n.4, p.21-25 1992.

7. FRANCO, R.C. Capacidade de corte da lima Flexofile usada manualmente e acoplada ao sistema rotatório Endo-Gripper em canais simulados. Taubaté, 2005. 52f. Monografia (Trabalho de conclusão de curso) - Departamento de Odontologia da Universidade de Taubaté.

8. HENNEQUIN, M.; ANDRE, J.F.; BOTTA, G. Dentin removal efficiency of six endodontic Systems: a quantitative comparison. J. Endod.; v.18, n.12, p.601-4, 1992.

9. LAGE-MARQUES, J.L.; ANTONIAZZI, J.H. Técnica endodôntica. Versão Eletrônica da Técnica de Endodontia da Faculdade de Odontologia da Universidade de São Paulo. [CDROM]. São Paulo: Ajna Interactive Ltda; 2002.

10. LEVY, G.; ABOU-RASS, M. Endodontic file design and dynamics in automated root canal preparation. Alpha Omegan v.8, n.3, p.68-72, 1990.

11. MEDEIROS, J. M. F.; LIMA, J. P.; BOMBANA, A. C. Analysis by scanning electron microscopy of the cutting surface changes on endodontics files according two methods for sterilizing and number of use. Act Report/Brazilian Synchrotron Light Laboratory, v.6, p. 267-8, 2002. 
12. MEDEIROS, J.M.F.; SIMI JR, J.; RISSO, V.A. Estudo comparativo mediante pesagem de duas técnicas de preparo de canais radiculares curvos com um tipo de instrumento endodôntico. Rev. Odontol. UNAERP v.3, n.1, p.11-16, 2000.

13. MORRISON, S.W.; NEWTON, C.W.; BROWN JR, C.E. The effects of steam sterilization and usage on cutting efficiency of endodontic instruments. J Endod, v.15, n. 9, p. 427-31, 1989.

14. PAIVA, J.G.; ANTONIAZZI, J.H. Endodontia. Bases para a prática clínica. 2 ed. São Paulo: Artes Médicas, 1991. 886p.

15. PALLOTARC; MACHADO MLBBL; MACHADO, M.E.L. Avaliação e comparação do poder de corte das limas Nitiflex e Flexofile em dentes naturais. Ecler Endodontics v.1, n.3, Set. 1999.

16. PESCE, H.F. Avaliação comparativa “in vitro", mediante a pesagem de dentes humanos, da eficiência de corte das limas Trifile e Flexofile, segundo o número de uso e o operador. (Contribuição ao Estudo). São Paulo, 1990. 67p. Tese (Livre Docência em Endodontia) - Faculdade de Odontologia da Universidade de São Paulo.

17. PESSOA, O.F. Análise comparativa, mediante a pesagem, de dentes humanos extraídos, da instrumentação de canais radiculares por especialistas em Endodontia, clínicos gerais e acadêmicos de Odontologia. São Paulo, 1993. 73p. Dissertação (Mestrado em Endodontia). Faculdade de Odontologia da Universidade de São Paulo.

18. ROANE, J.B.; SABALA, C.L.; DUNCANSON JR, M.G. The balanced force. Concept for instrumentation of curved canals. J. Endod v.11, n.5, p.203-211, May 1985.

19. SERENE, T.P.; ADAMS, J.D.; SAXENA, A. Nickel-titanium instruments: applications in endodontics. St Louis, Ihiyama: Euro-America, 1995. $112 \mathrm{p}$.

20. SCHÄFER, E. Relationship between design features of endodontic instruments and their properties. Part l. Cutting efficiency. J Endod v.25, n.1, p.52-55, Jan. 1999.

21. SILVA, E. A. B.Avaliação comparativa da capacidade eperda de corte de limas $K$ de aço inoxidável (Flexofile) e de níquelTitânio(Nitiflex). Taubaté, 2001. 80f. Dissertação (Mestrado em Odontologia) - Departamento de Odontologia da Universidade de Taubaté.

22. SOUZA, V.; BARBOSA, H.G.; HOLLAND, R.; DEZAN JUNIOR, E.; NERY, M.J.; OTTOBONI FILHO, J.Á.; BERNABE, P.F.E. Eficiência de corte alguns tipos de limas endodônticas. Rev Ciências Odontol v.1, n.1, p.65-74, 1998.

23. SYDNEY, G.B.; BATISTA, A.; MELO, L.L. Alargadores para contra-ângulo: uma opção como auxiliar no preparo do canal radicular. Rev. Bras. Odontol v.51, n.6, p.41-44, nov./dez. 1994.

24. TEPEL, J.; SCHAFER, E. Endodontic hand instruments: cutting efficiency, instrumentation of curved canals, bending and torsional properties. Endod. Dent. Traumat v.13, n.5, p.201210, May 1997.

25. TEPEL, J.; SCHAFER, E.; HOPPE, W. Properties of endodontic hand instruments used in rotary motion. Part 1. Cutting efficiency. J. Endod. v.21, n.8, p.418-21, Aug. 1995a.

26. TEPEL, J.; SCHAFER, E.; HOPPE, W. Root canal instruments for manual use: cutting efficiency and instrumentation of curved canals. Int. Endod. J v.28, p.68-76, Mar. 1995b. 